Anuario de

Derechos Humanos 2005 


\section{Chile Solidario: El Desafío de Construir un Sistema de Protección Social a partir de una Perspectiva de Derechos}

Augusto Quintana Benavides*
"...Leroy prosiguió: (...) - Ahora bien, nuestro siglo nos ha hecho comprender algo enorme: el hombre no es capaz de cambiar el mundo y nunca lo cambiará. Es la conclusión fundamental de mi experiencia de revolucionario. Conclusión, por otra parte aceptada tácitamente por todo el mundo. Pero hay otra que va más lejos: el hombre no tiene derecho a cambiar lo que Dios ha creado. Hay que ir hasta el final de esta prohibición" ${ }^{\prime 1}$.

\section{La Misión de Subvertir el Desorden Social que Provoca la Extrema Pobreza}

L as palabras de Milan Kundera nos sugieren que la mentalidad fatalista no puede ser la última expresión de un ser racional y que siempre será posible acudir a la creencia de restaurar un orden naturalmente igualitario que, en forma artificial y arbitraria, hemos subvertido. Esto es lo que acontece con la pobreza o, mejor dicho, con la condición de pobreza en la cual se encuentra inmersa una porción significativa de la población humana.

Esta es la primera y principal significación que posee "Chile Solidario", que surge $\mathrm{e}^{2}$ primero como "programa presupuestario" a partir del año 2002 (el denominado "Programa Puente") y, ahora, se desarrolla como un emergente "sistema de protección social", investido como tal merced a la reciente Ley $N^{\circ} 19.949$, de 2004, que establece un sistema de protección social para familias en situación de extrema pobreza denominado "Chile Solidario" ${ }^{3}$. En efecto, esta ley aparece como un paso relevante para poner fin -esperamos en forma definitiva- a la irrelevancia histórica y política de las personas que viven en condiciones de indigencia, a la hora de erigirse en sujetos beneficiarios de las políticas públicas. Es un contrasentido, pues quienes más requerirían de la acción solidaria por parte de los agentes del Estado, antes de la puesta en marcha de "Chile Solidario", no percibían la totalidad de las transferencias monetarias previstas en nuestro ordenamiento jurídico para esta categoría social ni eran receptores de las prestaciones sociales de los distintos servicios públicos y municipalidades, o sólo las percibían en forma fragmentada.

Tenemos que tener presente que, desde un punto de vista estrictamente económico, una persona o familia no debiera encontrarse en una

\footnotetext{
* Abogado y Magíster en Derecho Público, Profesor Asistente de Derecho Constitucional, Facultad de Derecho, Universidad de Chile, fue Secretario Ejecutivo de Chile Solidario.

Actualmente se desempeña como Subgerente Legal de la CORFO.
}

Ver las notas de este texto a partir de la página 95.

Este comentario, junto con el documento principal a que se refiere, están disponibles en formato digital www.anuariocdh.uchile.cl 
situación de extrema pobreza si estuviera plenamente vinculada a las redes sociales $y$, a modo de consecuencia, incorporara como ingreso permanente los distintos subsidios estatales asignados a las personas de escasos recursos: pensiones asistenciales, subsidio familiar, etc., los cuales sumados aproximarían el ingreso familiar al monto de 1 dólar americano diario por persona, para considerarlos pobres pero no indigentes. Sin embargo, la marginalidad social, en teoría inexplicable, es una realidad factual que involucraba a miles de familias y personas, todo ello ante la histórica pasividad de los agentes públicos y de la mayor parte de los integrantes de la comunidad nacional.

El lector podrá apreciar que el uso de las expresiones verbales en tiempos pasados obedece a la creencia empíricamente corroborada que, merced a las políticas sociales de última generación, entre las cuales la creación del sistema de protección social (SPS) denominado "Chile Solidario" es su cúspide lógica, miles de familias en nuestro país están abandonando la condición de indigencia. En efecto, un dato duro que emerge a partir de la IX Encuesta de Caracterización Socioeconómica Nacional, CASEN 2003, es que, en un contexto de desaceleración económica inaugurado a partir del año 1997, se redujo el porcentaje de indigentes desde un $5,7 \%$ en el año 2000 a un 4,7\% en el año $2003^{4}$. Si bien este resultado se condice con las expectativas de los organismos especializados ${ }^{5}$, no deja de ser cierto que la reducción de un punto porcentual de indigencia se explica por el criterio de focalización avanzado impuesto a las políticas sociales a partir del año 2000.

En suma, la marginalidad social existe, pero no por un designio divino ni menos por alguna fatalidad del destino o la naturaleza de las cosas. Tal marginalidad es producto de muchos factores, entre éstos, la displicencia por parte de la organización del Estado, incluyendo a las municipalidades, para enfrentar en forma sistemática, radical y definitiva este problema.

Es en esta perspectiva que la aprobación de la Ley $N^{\circ} 19.949$ cobra una centralidad histórica, no tanto porque proporcione nuevos beneficios o servicios a esta familias sino porque el Estado se impone el deber que las transferencias monetarias y las prestaciones de servicios que integran la red social del Estado sean efectivamente asequibles a ellas. Chile Solidario es, en este entendimiento, una reforma profunda al Estado, el cual ya no podrá ignorar sistemáticamente a las personas y familias más desamparadas como era perfectamente posible antes de su promulgación.

Es efectivo que un par de años antes de la promulgación de esta ley comenzó a implementarse el Programa Puente (del cual hablaremos más adelante), que contiene varios aspectos que definen y estructuran el emergente sistema de protección social (SPS). Sin embargo, el Programa Puente, que es coordinado a nivel nacional por el FOSIS e implementado a nivel comunal con el concurso de las Municipalidades, tiene a nuestro juicio un carácter parcial y a la par provisional que amerita un esfuerzo 
permanente en el tiempo y, por tanto, no supeditado al período que dura el mandato presidencial del Gobierno del Presidente Lagos. Este salto desde un programa social a un sistema de protección social es, probablemente, un legado político e histórico que los sucesivos gobiernos deberán perfeccionar para hacer efectivo, en el corto plazo, el desafío país de construir una convivencia social en la cual no exista la contingencia social denominada "extrema pobreza".

\section{Aspectos más Relevantes del Emergente SPS "Chile Solidario"}

"Chile Solidario" representa un punto de inflexión respecto de las políticas sociales desarrolladas en la última década del siglo XX, particularmente por las siguientes razones:

1. Porque se eleva el criterio de "focalización" a su máxima expresión, asegurando, en primer lugar, a las familias que viven en condiciones de indigencia, una serie de derechos, a la sazón: i) derecho a transferencias monetarias por parte del Estado, si se cumple con los requisitos establecidos en las normas jurídicas que los regulan, que pueden consistir en: el subsidio familiar ${ }^{6}$, las pensiones asistenciales de vejez e invalidez, el "bono de protección" de naturaleza temporal que beneficia a las familias que ingresen al sistema entre los años 2002 y $2005^{8}$ y el "bono de egreso" para las familias que cumplan con las condiciones mínimas de vida exigidas por el sistema, dentro del plazo de dos años contados desde su ingreso a éste ${ }^{9}$; ii) acceso asegurado a subsidios indirectos, es decir, que no importan un incremento patrimonial para el beneficiado: el subsidio al pago del consumo de agua potable y de servicio de alcantarillado de aguas servidas ${ }^{10}$ y el subsidio pro retención escolar $^{11}$; iii) acceso preferente a acciones o prestaciones sociales que se implementen o coordinen a través de "Chile Solidario"12, y, nosotros agregamos, iv) derecho a apoyo psicosocial por parte de un profesional calificado ${ }^{13}$.

2. Porque, en una primera fase la intervención social se concentra en "familias" más que en personas u otras categorías sociales. Si bien este criterio no es excluyente, toda vez que la propia ley admite que "personas en situación de extrema pobreza" puedan ser beneficiarias del sistema ${ }^{14}$, lo cierto es que en su primera fase de implementación (años 2002-2005), según se dispone en el artículo $1^{\circ}$ transitorio de la ley, sólo se contempla el ingreso de 225.073 "familias" al sistema "Chile Solidario".

3. Porque se adopta la política de transferencias monetarias "condicionadas", es decir, que se espera de parte del beneficiario, como contrapartida de la transferencia, un comportamiento o una conducta que importe un cambio de actitud respecto de sí misma o su entorno que, en este caso, sean aptos para superar su condición de extrema pobreza y mejorar sustancialmente sus condiciones de vida $^{15}$. Asimismo, el SPS contempla, en el artículo $2^{\circ}$ transitorio de 
la ley y a modo de estímulo, un "bono de egreso" para quienes cumplan las 53 condiciones mínimas de vida, equivalente al valor del subsidio familiar y por un lapso de tres años.

4. Porque el Estado rompe con el principio de pasividad para dar paso a una atención directa, inmediata y personalizada a los beneficiarios. Esta faceta del Programa Puente es, probablemente, el factor crítico para el éxito de la estrategia de intervención familiar merced al "apoyo psicosocial" que, según dispone el artículo $4^{\circ}$, consiste "en un acompañamiento personalizado a los beneficiarios incorporados a "Chile Solidario", por parte de un profesional o técnico idóneo, con el objeto de promover el desarrollo de las habilidades personales y familiares necesarias para satisfacer las condiciones mínimas de calidad de vida, definidas por el reglamento de esta ley, y en una estrategia de intervención destinada a fortalecer la vinculación efectiva de los beneficiarios con las redes sociales y el acceso a los beneficios que están a su disposición". La labor a cargo del profesional o técnico, con arreglo a una metodología que define MIDEPLAN, es clave para que cada uno de los miembros de las familias que viven en condiciones de pobreza reconozca las habilidades, talentos y capitales (físico, humano y social) que dispone para emerger y acceder a mejores condiciones de vida.

5. Porque se impulsa una política social que coordina a todos los organismos de la Administración del Estado, incluyendo a las municipalidades ${ }^{16}$ y, eventualmente, a la sociedad civil ${ }^{17}$. Si bien es cierto que a MIDEPLAN le asiste, entre otras funciones, la administración, coordinación, supervisión y evaluación del SPS, es claro que para la implementación del sistema esa Secretaría de Estado, conforme lo prescrito en el artículo $2^{\circ}$ de la ley, debe celebrar convenios con las Municipalidades del país en el ámbito de su respectivo territorio $y$, excepcionalmente y por razones fundadas, con otros órganos del Estado o entidades privadas sin fines de lucro. En los hechos, la estrategia de intervención familiar diseñada por la autoridad central es implementada bajo la dirección de las municipalidades, conforme a convenios que ellas suscriben, primero con el FOSIS y, una vez publicada la ley, con MIDEPLAN ${ }^{18}$.

\section{La Perspectiva de Derechos en Chile Solidario}

Una de las principales novedades -y fortalezas- de Chile Solidario es que goza de lo que en el Foro de Equidad Social -reunido a instancias del B.I.D.- denominamos "normatividad en sentido fuerte"19, es decir, que los aspectos centrales de esta política pública se encuentran regulados en normas jurídicas de naturaleza permanente y no quedan entregados a una mayor discrecionalidad por parte de los entes públicos encargados de su implementación; de manera tal que, sin normatividad en sentido fuerte, no existe perspectiva de derechos en las políticas públicas. $\mathrm{O}$, a contrario sensu, una política pública que es implementada en base a una normatividad débil o mínima no tiene la virtud de generar 
derechos permanentes a favor de los supuestos beneficiarios, cuyo goce efectivo, en última instancia, queda entregado a la decisión discrecional, muchas veces teñida de connotaciones políticas o electorales y en definitiva ajenas a la razón de ser de las políticas públicas.

Esta normatividad en sentido fuerte del SPS "Chile Solidario" proviene de diversas fuentes normativas, legales y reglamentarias, que definen los aspectos centrales de esta política social que aseguran su sustentabilidad en el tiempo ${ }^{20}$ y la imbuyen de una perspectiva de derechos $^{21}$ en los términos que más adelante se describen.

En esta perspectiva de derechos es crucial resaltar que la permanencia temporal de la política social no quede entregada a los vaivenes de la economía y menos pueda ser suprimida en períodos de crisis. A esto se le denomina "política anti-cíclica", es decir, que actúa en forma preventiva a la agudización de las contingencias sociales que originan o facilitan la extensión de la extrema pobreza, a contrapelo de las "políticas pro-cíclicas" que se promueven en períodos de mayor bonanza y que se interrumpen cuando existen menos disponibilidades presupuestarias $^{22}$. Por ello no ha de extrañar que el tema del financiamiento de las políticas sociales sea un tema que está siempre presente en la inquietud de los organismos internacionales de derechos humanos. Así por ejemplo, el Comité de Derechos Económicos, Sociales y Culturales de las Naciones Unidas ("CDESC"), luego de congratularse por la aprobación y ejecución de programas específicos para mejorar la situación de los grupos más pobres de la sociedad chilena, como Chile Solidario y el Plan AUGE, recomienda al Estado de Chile que "vele por que se asignen suficientes recursos a la consecución de las metas y objetivos establecidos en el marco de los programas Chile Solidario y Chile Barrio" ${ }^{23}$. Sobre el particular, merece destacarse que con antelación a la sanción de la Ley $N^{\circ} 19.949$, entró en vigencia en nuestro país la Ley $\mathrm{N}^{\circ} 19.888$, que establece financiamiento necesario para asegurar los objetivos sociales prioritarios del Gobierno ${ }^{24}$, específicamente el SPS Chile Solidario y el Plan Auge, para lo cual se introdujo, principalmente, una reforma de naturaleza temporal al impuesto de las ventas y servicios (IVA) alzando el gravamen entre el $1^{\circ}$ de octubre de 2003 y el $1^{\circ}$ de enero de 2007 desde un $18 \%$ a un $19 \%$, de manera que en esta última fecha cobre vigencia nuevamente el guarismo anterior. Por lo mismo, creemos que el financiamiento de Chile Solidario está en principio asegurado; empero, esta aseveración optimista debe reevaluarse habida cuenta del relevante costo presupuestario que exige el financiamiento de la red de prestaciones sociales orientada a satisfacer las denominadas condiciones mínimas del Programa Puente, particularmente en lo que atañe a las dimensiones de habitabilidad, trabajo e ingreso, según se verá más adelante.

Un aspecto central de esta perspectiva de derechos es que el universo de beneficiarios, junto con coincidir con la totalidad de familias y personas que se encontraban a la época de su puesta en marcha en la condición de extrema pobreza, o que en el futuro caigan en esa 
categoría social, está predeterminado en la le ${ }^{25}$, aunque para el solo efecto de su implementación, según se prescribe en el artículo $1^{\circ}$ transitorio de la ley, se contempla una cobertura gradual año tras año (225.073 familias deben ser incorporadas hasta el año 2005) y, con posterioridad, según dispone el inciso final del artículo $3^{\circ}$ de la ley, "MIDEPLAN, mediante decreto expedido por orden del Presidente de la República y suscrito además por el Ministerio de Hacienda, identificará la cobertura anual de los beneficiarios, según la disponibilidad de recursos consultados en la Ley de Presupuestos y conforme al reglamento de la presente ley".

Otra faceta que debe destacarse es la naturaleza contractual que vincula a las familias con los agentes públicos y, por consiguiente, la íntima relación que se produce entre derechos de los beneficiarios y las obligaciones que asumen por ingresar al sistema. En efecto, el inciso primero del artículo $5^{\circ}$ de la ley dispone que para ingresar y participar en el SPS, las familias y personas calificadas "deberán manifestar expresamente su voluntad en tal sentido, así como la de cumplir las condiciones del sistema" $y$, agrega esa norma legal, que tal manifestación de voluntad se realizará "mediante la suscripción de un documento de compromiso" que, según las normativa complementaria, deben suscribir la jefa de hogar (prioritariamente) con el profesional o técnico que presta la labor de apoyo psicosocial. Esta naturaleza contractual del ingreso al sistema se orienta en la dirección recomendada por la doctrina especializada ${ }^{26}$, esto es, que la membresía a un sistema de protección social y, por tanto, la calidad de sujeto activo de ciertos derechos, no sea un premio para el que ningún esfuerzo desea realizar para salir de la contingencia social que el sistema pretende cubrir sino para el que realmente pretenda ser agente de su propia promoción humana. Por consiguiente, al ingresar a Chile Solidario el beneficiario asume una serie de obligaciones que se traducen en un esfuerzo por cumplir las 53 condiciones para egresar del sistema. Así, el supuesto metodológico es que una familia (o persona) que cumpla con las condiciones mínimas de vida que exige el SPS ha logrado superar su condición de indigencia, no sólo en términos monetarios (ingresos) sino en una perspectiva más integral y sostenible en el tiempo.

En suma, existe perspectiva de derechos en las políticas públicas, principalmente derechos sociales aunque, en términos más amplios, puede englobarse en la noción de "derecho al desarrollo" ${ }^{27}$, cuando el objetivo central y prioritario de dichas políticas es facilitar el goce efectivo de un derecho, entendido éste como una atribución subjetiva, eventualmente exigible a través de una acción jurisdiccional, merced a criterios de normatividad en sentido fuerte que aseguran una política pública de mediano y largo plazo, entendida ésta como un asunto de Estado y fundada en un amplio consenso político, que sirven de base a un compromiso presupuestario de carácter anti-cíclico e imbuida de criterios de eficiencia, eficacia y "accountability". Esta perspectiva, finalmente, se traduce en la aprobación de un Catálogo de Derechos 
bajo un régimen de perfeccionamiento continuo o, en su caso, de revisión fundada (principio de razonabilidad) en un contexto de una democracia deliberativa ${ }^{28}$.

En lo que atañe al Catálogo de Derechos es de mencionar que, tratándose del SPS Chile Solidario, estos derechos son los que derivan de las 53 condiciones mínimas que a continuación citaremos. De su sola lectura se colige la naturaleza integral de la metodología de intervención social y, por ende, el supuesto de que para abandonar la situación de extrema pobreza no basta la sola consideración del factor ingreso monetario. Asimismo, es dable apreciar, por la extensión de las materias involucradas, cómo el cumplimiento de estas condiciones básicas de vida tensiona a la totalidad del aparato público para generar una oferta de prestaciones que estén al alcance de los beneficiarios del sistema, para lo cual no sólo debe asegurarse el acceso (prioritario) de los beneficiarios del sistema a los distintos programas sociales que se vinculan con cada una de estas condiciones mínimas, sino que también, en no pocos casos, habría que diseñar e implementar nuevos programas sociales o rectificar los existentes.

Así, las 53 condiciones básicas de vida, ordenadas en base a las siete dimensiones, $\operatorname{son}^{29}$ :

\section{Dimensión de Identificación:}

1. Que todos los miembros de la familia estén inscritos en el Registro Civil.

2. Que todos los miembros de la familia tengan cédula de identidad.

3. Que la familia tenga su ficha CAS vigente en la Municipalidad de su domicilio.

4. Que todos los hombres de la familia mayores de 18 años tengan su situación militar al día.

5. Que todos los miembros adultos de la familia tengan sus papeles de antecedentes regularizados.

6. Que los miembros de la familia que presenten alguna discapacidad, la tengan debidamente certificada por el COMPIN y estén inscritos en el Registro Nacional de la Discapacidad, en el caso que la discapacidad lo amerite.

\section{Dimensión de Salud:}

1. Que la familia esté inscrita en el Servicio de Atención Primaria de Salud.

2. Que las embarazadas tengan sus controles de salud al día.

3. Que los niños y niñas de 6 años o menos tengan sus vacunas al día.

4. Que los niños niñas de 6 años o menos tengan sus controles de salud al día. 
5. Que las mujeres de 35 años y más tengan el examen de papanicolau al día.

6. Que las mujeres que usen algún método anticonceptivo estén bajo control médico.

7. Que los adultos mayores de la familia estén bajo control médico en el consultorio.

8. Que los miembros de la familia que sufren alguna enfermedad crónica, se encuentren bajo control médico en el centro de salud que corresponda.

9. Que el o los miembros con discapacidad, susceptibles de ser rehabilitados, estén participando en algún programa de rehabilitación.

10.Que los miembros de la familia estén informados en materia de salud y autocuidado.

Dimensión de Educación:

1. Que los niños y niñas en edad preescolar asistan a algún programa de educación de párvulos.

2. Que en presencia de madre trabajadora y en ausencia de otro adulto que pueda hacerse cargo de su cuidado, el o los niños menores de 6 años se encuentren incorporados a algún sistema de cuidado infantil.

3. Que los niños de hasta 15 años de edad asistan a algún establecimiento educacional.

4. Que los niños que asisten a educación preescolar, básica o media sean beneficiarios de los programas de asistencia escolar que correspondan.

5. Que los niños mayores de 12 años sepan leer y escribir.

6. Que el o los niños con discapacidad que estén en condiciones de estudiar se encuentren incorporados al sistema educacional, regular o especial.

7. Que exista un adulto responsable de la educación del niño y que esté en contacto regular con la escuela.

8. Que los adultos tengan una actitud positiva y responsable hacia la educación y la escuela, al menos reconociendo la utilidad de la participación del niño en procesos educativos formales.

9. Que los adultos sepan leer y escribir.

Dimensión de Dinámica Familiar:

1. Que existan en la familia prácticas cotidianas de conversación sobre temas como hábitos, horarios y espacios de recreación.

2. Que la familia cuente con mecanismos adecuados para enfrentar conflictos. 
3. Que existan normas claras de convivencia al interior de la familia.

4. Que exista una distribución equitativa de las tareas del hogar.

5. Que la familia conozca los recursos comunitarios y los programas de desarrollo disponibles en la red local.

6. Que en caso que exista violencia intrafamiliar, las personas involucradas directamente en esta situación estén incorporadas a algún programa de apoyo.

7. Que la familia que tiene interno un niño en algún sistema de protección, lo visite regularmente.

8. Que la familia que tiene algún joven privado de libertad, lo apoye y colabore en el programa de rehabilitación.

\section{Dinámica de Habitabilidad:}

1. Que la familia tenga su situación habitacional clara en relación con la tenencia del sitio y la vivienda que habitan.

2. Si la familia quiere postular a vivienda, que se encuentre postulando.

3. Que cuenten con agua no contaminada.

4. Que cuenten con un sistema de energía adecuado.

5. Que cuenten con un sistema de eliminación de excretas adecuado.

6. Que la casa no se llueva, no se inunde y esté bien sellada.

7. Que la vivienda cuente, al menos, con dos piezas habitables.

8. Que cada miembro de la familia tenga su cama con equipamiento básico.

9. Que cuenten con equipamiento básico para la alimentación de los miembros de la familia.

10.Que dispongan de un sistema adecuado de eliminación de basura.

11. Que el entorno de la vivienda esté libre de contaminación.

12.Que la familia acceda al subsidio al pago del consumo del agua potable, si corresponde.

Dinámica de Trabajo:

1. Que al menos un miembro adulto de la familia trabaje de forma regular y tenga una remuneración estable.

2. Que ningún niño menor de 15 años abandone los estudios por trabajar.

3. Que las personas que se encuentren desocupadas estén inscritas en la oficina Municipal de Información Laboral (OMIL). 
Dinámica de Ingresos:

1. Que los miembros de la familia que tengan derecho a SUF (subsidio único familiar), lo obtengan.

2. Que los miembros de la familia que tengan derecho a Asignación Familiar, la obtengan.

3. Que los miembros de la familia que tengan derecho a PASIS (pensión asistencial), la obtengan.

4. Que la familia cuente con ingresos económicos superiores a la línea de la indigencia.

5. Que la familia cuente con un presupuesto organizado en función de sus recursos y necesidades prioritarias.

En definitiva, es por todas estas consideraciones que el SPS creado mediante la Ley $\mathrm{N}^{\circ} 19.949$, sin perjuicio de los necesarios perfeccionamientos que sería conveniente introducirle, recoge en lo sustancial una perspectiva de derechos.

\section{Conclusiones}

1. La Ley $N^{\circ} 19.949$ que crea el sistema de protección social denominado "Chile Solidario" es un paso trascendente en el camino de asegurar los Ilamados "derechos sociales" o, en su caso, del derecho al desarrollo.

2. El impacto de este sistema de protección social seguramente fortalecerá la tendencia a la disminución de los niveles de extrema pobreza, a una cifra inferior a la advertida en la última Encuesta CASEN realizada el año 2003 y que arrojó que un 4,7\% de los chilenos viven en esa condición socioeconómica.

3. Sin perjuicio de lo anterior, estimamos que la normativa que rige al SPS Chile Solidario amerita algunos perfeccionamientos, entre los cuales nos permitimos sugerir los siguientes: i) para adecuar de mejor modo la constitucionalidad del sistema estimamos que las siete dimensiones (u otras cuya creación se estipule) que aglutinan a las actuales 53 condiciones mínimas de vida que los beneficiarios se comprometen a cumplir, debieran contemplarse en la propia ley y las mencionadas condiciones mínimas en el reglamento; ii) debiera preverse a futuro, en forma gradual, un mayor rol de las municipalidades en el diseño y administración de las estrategias de intervención social, según sean la idoneidad de los recursos humanos de los municipios y la realidad socio-económica de la respectiva comuna, admitiendo la posibilidad de que la autoridad central transfiera recursos presupuestarios al efecto; iii) en las fases sucesivas, esto es a partir del año 2006, debe asegurarse la cobertura $y$, por ende, el ingreso al sistema de las personas en situación de extrema pobreza que viven solas y de las personas "en situación de calle"; iv) debe modificarse la normativa para posibilitar que la 
denominada sociedad civil tenga un rol más activo en la supervisión y evaluación del sistema para asegurar, de mejor modo, la eficiencia y eficacia de la estrategia de intervención, de las transferencias monetarias y el acceso a las prestaciones sociales, en la lógica de un sistema complejo de responsabilidad administrativa conocido como accountability en el mundo anglosajón; y v) les asiste a las instituciones públicas involucradas en la intervención social y a las entidades públicas que deben otorgar prestaciones sociales vinculadas a las condiciones mínimas, reexaminar las condiciones de accesibilidad, calidad y pertinencia de los programas sociales para que las personas en situación de extrema pobreza tengan la posibilidad real de cumplir las condiciones mínimas que exige el sistema. Esto último involucra, por cierto, el compromiso presupuestario por parte del Estado.

\section{Notas}

1 Milan KUNDERA: "La identidad" (Tusquets Editores, S.A., Barcelona, 1998, página 148).

2 Esta iniciativa surge, entre otros estudios relevantes, teniendo a la vista el diagnóstico de las políticas sociales y las propuestas que se contienen en un documento elaborado por MIDEPLAN denominado "Estrategia de intervención integral a favor de familias en extrema pobreza" (enero de 2002).

3 Publicada en el Diario Oficial con fecha 5 de junio de 2004.

4 Ver el documento elaborado por la División Social de MIDEPLAN intitulado "Principales Resultados CASEN 2003", en www.mideplan.cl.

5 Según el estudio de la CEPAL denominado "Hacia el objetivo del milenio de reducir la pobreza en América Latina y el Caribe" (Santiago de Chile, 2003), Chile es una de las siete naciones de la región que está en condiciones de cumplir la Meta del Milenio de reducir a la mitad, para el año 2015, la proporción de la población que vive con menos de un dólar diario, es decir, que se encuentran en condiciones de indigencia utilizando el parámetro del ingreso.

6 Regulado en la Ley $N^{\circ} 18.020$, de 1981.

7 Contemplada en el Decreto Ley N869, de 1975.

8 Este "bono de protección" se contempla en el artículo $2^{\circ}$ transitorio de la ley.

9 Idem anterior.

${ }^{10}$ Regulado en la Ley $N^{\circ} 18.778$, de 1989.

${ }^{11}$ Asegurado por la Ley $N^{\circ} 19.873$, de 2003.

12 Conforme a la Ley N¹9.986, Ley de Presupuestos del Sector Público Año 2005, al Sistema Chile Solidario le corresponde coordinar, además del Programa de Apoyo Integral a Familias Indigentes (Programa Puente), los siguientes programas: Programa de Generación de Ingresos e inclusión Social (FOSIS); Programa INTEGRA, Programa de Salud Oral (JUNAEB), Programa Proempleo (Subsecretaría de Trabajo), Habilidades para la Vida y Escuelas Saludables (JUNAEB), Programa de Salud Chile Solidario (FONASA), Programa de Educación Prebásica (Subsecretaría de Educación), Programa de Educación Media (Subsecretaría de Educación), Programa de Ayudas Técnicas (FONADIS), PRODEMU (Servicio Nacional de la Mujer), Programa de Alimentación y Útiles Escolares (JUNAEB), Bono de Producción Agrícola y Familiar (INDAP), Programa de Habitabilidad Chile Solidario y Programa de Identificación Chile Solidario.

${ }^{13}$ El derecho a la atención de un profesional calificado es un elemento central del denominado "Programa Puente" y, como tal, del sistema de protección social "Chile Solidario" y, a no dudar, refleja la opción del Gobierno del Presidente Lagos de promover una política de superación de la indigencia que no descanse primariamente en transferencias monetarias, como propiciaba la oposición. Una estrategia para la superación de la extrema pobreza debe estar basada en una concepción más integral de la pobreza e indigencia, en tanto 
ésta no es consecuencia exclusivamente de desigualdades en la distribución de dinero (capital físico) sino también de capital humano (educación y capacitación laboral) y de capital social (participación en distintas redes e integración social). En palabras del propio Presidente Lagos: “... el debate se produjo si lo que debíamos hacer era mandar un cheque todos los meses, porque si indigente es el que gana menos de tanto, mándele un cheque por la diferencia y lo sacamos de la indigencia. O intentábamos algo distinto." (Palabras de S.E. el Presidente de la República, Ricardo lagos, en Tercer Encuentro Nacional de Jefes de Unidades de Intervención Familiar del Programa Chile Solidario, 4 de marzo de 2005. Véase en $w w w . m i d e p l a n . c l)$.

${ }^{14}$ La Ley N¹9.949, en diversos artículos, da cuenta que las "personas en situación de extrema pobreza" que no forman parte de una familia pluripersonal pueden ser beneficiarios del sistema, a saber: i) el artículo $2^{\circ}$ que enuncia las acciones que el sistema contempla; ii) el artículo $5^{\circ}$ que regula el mecanismo de ingreso al sistema de protección social; iii) el artículo $6^{\circ}$ en relación con los titulares de datos personales que serán almacenados en el Registro de Información Social que allí se crea; iv) el artículo $8^{\circ}$ en relación con el subsidio al consumo de agua potable y de servicio de alcantarillado de aguas servidas, y v) el artículo $5^{\circ}$ transitorio, por medio del cual se asegura el derecho a percibir una pensión asistencial a las personas indigentes de 65 años o más que viven solos. Aclaramos que cuando nos referimos a "personas" en situación de extrema pobreza, para diferenciarlas de las "familias" que viven en esa condición, nos estamos refiriendo a dos categorías de personas que no integran el universo de beneficiarios que deben ingresar al sistema entre los años 2002 y 2005: a) las denominadas familias unipersonales, es decir, a personas con domicilio conocido que viven solas, y b) las "personas en situación de calle", esto es, las personas que no poseen una residencia fija o que viven en hospederías públicas o clandestinas, sean administradas por corporaciones o fundaciones o por personas naturales. Lo cierto es que la decisión del Gobierno de incorporar a las "familias" que, a la fecha de la realización de la Encuesta CASEN 2000 se encontraban en situación de extrema pobreza, se tradujo, en un primer momento, en que el proyecto de ley del Ejecutivo no contemplara a las demás personas indigentes como beneficiarios del sistema. Fue a instancias de la Secretaría Ejecutiva de Chile Solidario, a la época dirigida por el autor de estas líneas, durante la tramitación parlamentaria y con el respaldo del Ministro de MIDEPLAN señor Andrés Palma, que se rectificó el texto original en los términos que da cuenta la ley vigente para incluir dentro del sistema a todas las personas que se encuentren en condiciones de extrema pobreza.

15 La naturaleza "condicional" de las transferencias monetarias a las cuales tengan derecho las familias beneficiarias se deriva de lo dispuesto en el artículo $5^{\circ}$ de la ley, en la medida que para ingresar al SPS se requiere "cumplir las condiciones del sistema". La ley no precisa cuáles son esas condiciones. El Reglamento de esta ley, contenido en el Decreto Supremo $N^{\circ} 235$, de 25 de noviembre de 2004, de MIDEPLAN, publicado en el Diario Oficial con fecha 14 de marzo de 2005, en su artículo 17 inciso tercero, se limita a indicar que "las condiciones mínimas de calidad de vida consisten en objetivos mínimos a cumplir por parte de los beneficiarios incorporados a Chile Solidario, y dicen relación con las siguientes siete dimensiones o categorías de la vida familiar: Identificación, Salud, Educación, Dinámica Familiar, Habitabilidad, Trabajo e Ingresos". La circunstancia que ni la ley ni el reglamento determinen las condiciones que deben cumplir los beneficiarios nos parece que debe ser revisada en tanto tales condiciones son requisito para el goce de determinados derechos. Creemos que se ajusta más a lo dispuesto en la Constitución, en especial a lo dispuesto en el Artículo $19 \mathrm{~N}^{\circ} 26$ en relación con los Artículos 60 №20 sobre materias de ley y $32 N^{\circ} 8$ sobre potestad reglamentaria del Presidente de la República, las siete dimensiones antes aludidas debieran estipularse en la ley y las condiciones específicas de cada una de esas dimensiones en el reglamento.

16 En un principio la oposición política temía que la implementación de "Chile Solidario" pudiera emplearse como una estrategia electoral por parte del Gobierno en desmedro de las autoridades edilicias opositoras. Esta crítica se manifestó no sólo en la discusión parlamentaria sino en numerosos documentos y artículos de opinión que abogaban semánticamente por una mayor descentralización de las políticas sociales y eventualmente entregar la administración del Programa Puente a las municipalidades; verbigracia: i) INSTITUTO LIBERTADY DESARROLLO: "Programa Chile Solidario: una primera mirada" (Temas Públicos, 31 de mayo de 2002, véase en $w w w$.lyd.com); ii) INSTITUTO LIBERTADY DESARROLLO (Rosita CAMHI, Rodrigo CASTRO y Sebastián SOTO): "Programa Chile Solidario: análisis y comentarios" (Serie Informe Social №74, febrero de 2003, véase en www.lyd.com); iii) Rodrigo CASTRO F.: "Chile Solidario: Con más centralismo, pierden los pobres" (diario "La Segunda", 27 de octubre de 2003, véase en www.lasegunda.cl); iv) Nicolás FIGARI V.: "Proyecto de ley sobre Chile Solidario: ¿una política social centralizada?" (Fundación Jaime 
Guzmán E., en www.fjguzman.cl). El tiempo, algunas modificaciones a los preceptos del proyecto de ley consensuadas entre el Gobierno, la Asociación Chilena de Municipalidades y el Honorable Senador señor Cantero y, por último, la circunstancia que la totalidad de los municipios (de las comunas que, según la Encuesta CASEN 2000, poseyeran familias que debían beneficiarse con el SPS) ingresaran al sistema y el hecho que la dirección de la intervención está a cargo de un funcionario municipal designado por la propia municipalidad terminaron por despejar los resquemores. Este cambio de percepción se refleja en los siguientes artículos: i) INSTITUTO LIBERTAD: "Proyecto de ley que establece un sistema de protección social para familias en situación de extrema pobreza denominado Chile Solidario" (Asesoría Jurídico-Legislativa, 3 de mayo de 2004, véase en www.gobernabilidad.cl), y ii) INSTITUTO LIBERTAD: “Un sistema sin descentralización: La esperanza de Chile Solidario" (Opinión Política N²37, 3 de junio de 2004, véase en www.institutolibertad.cl). En este último artículo, el Instituto Libertad afirma que "aún falta por avanzar en la delegación de recursos a los gobiernos locales, que son, en definitiva, por expreso mandato constitucional, los encargados de satisfacer las necesidades de sus comunidades, adaptando los sistemas propuestos a las diversas realidades de cada una de las 344 del país". En nuestra opinión esta última faceta resaltada por el Instituto Libertad no parecía apropiada para la primera fase de Chile Solidario (2002-2005) entre otras razones por la circunstancia de que la idea propiciada por el Gobierno era aplicar uniformemente una intervención social en todo el país; porque cualquier alteración al Programa Puente en la actual fase hacía más compleja aún e, incluso, podía poner en riesgo la implementación del mismo; porque las municipalidades del país no poseen todas los mismos recursos humanos para implementar autónomamente un programa de esta magnitud, etc. Sin embargo, es claro que en las fases siguientes de implementación del SPS deberían consultarse modalidades de participación mayores para las municipalidades, aunque en forma escalonada según sean las capacidades de cada municipio y la calidad de las intervenciones que estén en condiciones de impulsar, todo ello con cargo a recursos presupuestarios que, en definitiva, son de todos los chilenos y, por lo mismo, la autoridad central es la llamada a administrar o transferir.

17 Una de las críticas que se vierten a "Chile Solidario" incide en la ausencia de una colaboración efectiva con los organismos de la sociedad civil o, al menos, en el discreto rol que se le asigna a ésta en la implementación del sistema. Así, pueden consultarse: i) ACCIÓN: "Notas para el debate sobre el sistema Chile Solidario" (Asociación Chilena de Organismos No Gubernamentales A.G., octubre de 2002, véase en www.sociedadcivil.cl), y ii) Leonardo MORENO: "El aporte de la sociedad civil a la reducción de la pobreza" (Fundación para la Superación de la Pobreza, 8 de julio de 2004, véase en www.fundacionpobreza.cl). En este último texto se critica la actual normativa que rige el sistema de donaciones y la ausencia de una auténtica "democracia tributaria", en virtud de la cual los contribuyentes decidan el destino de sus impuestos, en la creencia de que con ello se multiplicarían los recursos (y la eficiencia en el gasto sería de esperar) orientados a la superación de la pobreza. Estas propuestas, independientemente de la conveniencia de extender la red del SPS a la sociedad civil con arreglo al principio de subsidiariedad, nos parece que deben apreciarse, más que como una crítica al diseño e implementación del SPS, como una propuesta que pueda ser considerada, en lo que sea pertinente y efectivo, para futuras fases de su implementación. No puede tampoco ignorarse que por mucho tiempo diversos organismos de la sociedad civil reclamaron justificadamente contra las autoridades estatales por el descuido en que éstas incurrían respecto de las personas en situación de extrema pobreza; sin embargo, la crítica se transmutó ahora hacia el otro extremo, esto es, del Estado ausente hacia el Estado omnipresente. Será la evaluación de resultados que se efectúe a la primera fase del SPS la que arrojará luces acerca la ecuación más afortunada y conveniente para una posible promoción de la sociedad civil por parte del Estado en estos dominios que no sea una nueva forma de asistencialismo a una burocracia no estatal.

${ }^{18} \mathrm{El}$ inciso primero del artículo $4^{\circ}$ transitorio dispone que "a partir de la entrada en vigencia de esta ley, los convenios celebrados por el Fondo de Solidaridad e Inversión Social, en el marco del Programa de Apoyo Integral a Familias Indigentes, se entenderán suscritos por MIDEPLAN, y serán aplicables a "Chile Solidario"". Esta norma refleja que lo que fue una estrategia de intervención temporal cuyo impulso se entregó al FOSIS, da paso a un sistema de protección social con alcances permanentes y más amplios de los previstos en el Programa de Apoyo Integral a Familias Indigentes ("Programa Puente"), que tenía un alcance temporal acotado hasta el año 2005 y sólo referido a las familias en situación de extrema pobreza.

${ }^{19}$ Véase el paper de Augusto QUINTANA BENAVIDES: "La perspectiva de los derechos en las políticas sociales" en www.iadb.org. También puede consultarse en esa página web nuestra ponencia en power point, con el mismo nombre, presentada ante el VI Foro de Equidad Social, Banco Interamericano de Desarrollo, Washington D.C., agosto de 2004. 
20 Para una adecuada comprensión de la importancia de asegurar la sustentabilidad en el tiempo de las políticas sociales puede consultarse Marco MIRA D'ERCOLE - Andrea SALVINI: "Towards sustainable development: the role of social protection" (OECD Social, Employement and Migration Working Papers №12, París, 2003).

${ }^{21}$ A esta misma conclusión arriban Ernesto COHEN, Rodrigo MARTíNEZ, Andrés FERNÁNDEZ y Marcelo ÁLVAREZ, cuando afirman lo siguiente: El enfoque metodológico utilizado por el Programa Puente "se fundamenta en la perspectiva de los "derechos sociales". Con ello, la solución de los problemas sociales y económicos son un imperativo ético y no una variable de ajuste de la política económica" "Análisis del Programa Puente 2002", División de Desarrollo Social de la CEPAL; Santiago de Chile, junio de 2003, Tomo I, página viii). Sin perjuicio de compartir esta aseveración, creemos que los autores citados coinciden en esa conclusión a partir de una lectura de las 53 condiciones que las familias beneficiarias deben cumplir, distribuidas en las dimensiones de vida familiar, identificación, habitabilidad, educación, salud, trabajo e ingreso, las que se conciben como una palanca para acceder al goce efectivo de determinados derechos sociales. Es más, la idea misma de "puente" que identifica al programa supone simbólicamente la conexión (un puente) entre las familias y sus derechos.

22 Para profundizar la relación que media entre los sistemas de protección social y la política económica en tiempos de crisis sugerimos las siguientes lecturas: i) Norman HICKS y Quentin WODON: "Protección social para los pobres en América Latina" (Revista de la CEPAL N73, abril de 2001, páginas 95 y sgtes.); ii) BANCO INTERAMERICANO DE DESARROLLO (Unidad Asesora sobre Pobreza y Desigualdad del Departamento de Desarrollo Sostenible): "Protección social para la equidad y el crecimiento" (marzo de 2000), y iii) Alberto ARENAS DE MESA y Julio GUZMÁN COX: "Política fiscal y protección social en Chile" (Revista de la CEPAL N81, diciembre de 2003, páginas 123 y sgtes.).

23 Informe sobre Observaciones Finales, de 26 de noviembre de 2005, aprobado por el Comité en su $33^{\circ}$ Período de Sesiones en su Examen de los Informes presentados por los Estados Partes de conformidad con los Artículos 16 y 17 del Pacto de Derechos Económicos, Sociales y Culturales. Ver en www.un.org. Chile Barrio es un programa orientado a proporcionar viviendas definitivas para las personas que viven en campamentos.

${ }^{24}$ Publicada en el Diario Oficial con fecha 13 de agosto de 2003. El tema del financiamiento de las políticas sociales es un tema que está siempre presente en la inquietud de los organismos internacionales de derechos humanos.

${ }^{25}$ En este punto cobran importancia las palabras de Arianna LEGOVINI y Ferdinando REGALIA cuando, en un artículo denominado "Targeted human development programs: investing in the next generation" (Banco Interamericano de Desarrollo, Departamento de Desarrollo Sostenible, Best Practices Series, septiembre de 2001, página 12), afirman que "care must be taken to avoid the discretionality that survey-based targeting systems are designed to prevent". Para estos efectos, los autores recomiendan una participación activa de la comunidad en la revisión de los resultados de la selección de beneficiarios y que tanto éstos como los no-beneficiarios debieran ser informados que la elegibilidad no está condicionada a un comportamiento electoral o a afiliación política.

${ }^{26}$ Así puede consultarse a John E. ROEMER, quien afirma que "surveys in many countries have shown that citizens support social transfers when the recipients are conceived of as 'deserving', in the sense that their unfortunate situation is not due to irresponsible behavior, but to bad luck or circumstances" ("Equalizing opportunities for human development (in one country)", Banco Interamericano de Desarrollo, Departamento de Desarrollo Sostenible, Technical Papers Series, Washington D.C., febrero de 2000, página 10).

27 La expresión "derecho al desarrollo" es una nomenclatura que posee alguna relevancia actual. Para estos efectos recomendamos la lectura del Informe del GRUPO DE TRABAJO SOBRE EL DERECHO AL DESARROLLO DE LA COMISIÓN DE DERECHOS HUMANOS DE LAS NACIONES UNIDAS titulado "Examen de los progresos alcanzados y los obstáculos encontrados en la promoción, la aplicación, el ejercicio y el disfrute del derecho al desarrollo. Estudios por países sobre el derecho al desarrollo (la Argentina, Chile y el Brasil)" (E/CN.4/2004/WG.18/3, de 23 de enero de 2004).

${ }^{28}$ Esta definición de política pública con perspectiva de derechos la vertimos en nuestra ponencia individualizada en la nota a pie $\mathrm{N}^{\circ} 19$.

${ }^{29}$ Mayores detalles fidedignos sobre estas condiciones básicas de vida y, en general, sobre la metodología de intervención social que emplea el Programa Puente pueden consultarse en las páginas www.mideplan.cl, www.chilesolidario.gov.cl, www.fosis.cl y www.programapuente.cl. 